\title{
Correction to: Scenario modeling of ammonia emissions from surface applied urea under temperate conditions: application effects and model comparison
}

\author{
Andreas Pacholski $[$ Johannes Doehler - Urs Schmidhalter - Thomas Kreuter
}

Published online: 12 October 2017

(C) Springer Science+Business Media B.V. 2017

\section{Correction to: Nutr Cycl Agroecosyst DOI 10.1007/s10705-017-9883-5}

The captions of figures 3-6 in the original publication are misplaced. The correct figure captions are as follows:

Fig. 3: Linear regression of simulated relative ammonia emissions by the dynamic model Volt'Air on measured relative ammonia emissions for the parameterization data set (three sites), modelling performance indicators: axis intercept and slope, coefficient of determination (R2), d-index (d), modelling efficiency (ME), root mean squared error (RMSE), and mean bias error (MBE).

The online version of the original article can be found under doi:10.1007/s10705-017-9883-5.

\section{A. Pacholski}

Institute of Ecology, Leuphana University, Scharnhorststr.

1, 21335 Lüneburg, Germany

\section{Present Address:}

A. Pacholski $(\square)$

EuroChem Agro GmbH, Reichskanzler-Müller-Str. 23,

68165 Mannheim, Germany

e-mail: andreas.pacholski@eurochemgroup.com

J. Doehler · T. Kreuter

Centre for Agriculture Application Research,

Stickstoffwerke Pisteritz GmbH, Wieseneck 7,

04451 Borsdorf OT Cunnersdorf, Germany

e-mail: johannes.dohler@skwp.de
Fig. 4: Linear regression of simulated relative ammonia emissions by the dynamic model Volt'Air on measured relative ammonia emissions for the validation data set (three sites), modelling performance indicators: axis intercept and slope, coefficient of determination (R2), d-index (d), modelling efficiency (ME), root mean squared error (RMSE), and mean bias error (MBE).

Fig. 5: Linear regression of simulated relative ammonia emissions by the statistical model on measured relative ammonia emissions for the parameterisation data set (three sites), modelling performance indicators: axis intercept and slope, coefficient of determination (R2), d-index (d), modelling efficiency (ME), root mean squared error (RMSE), and mean bias error (MBE).

Fig. 6: Linear regression of simulated relative ammonia emissions by the statistical model on measured

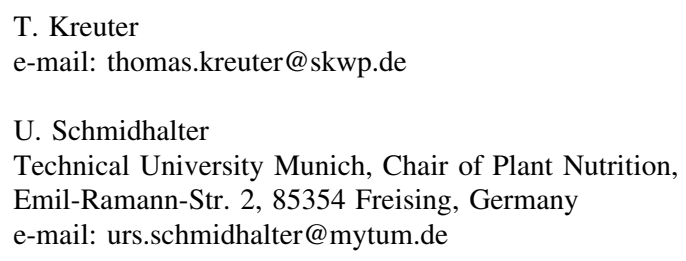


relative ammonia emissions for the validation data set (three sites), modelling performance indicators: axis intercept and slope, coefficient of determination (R2), d-index (d), modelling efficiency (ME), root mean squared error (RMSE), and mean bias error (MBE).

The original article was corrected. 